\title{
Oral Anticoagulation in Chronic Kidney Disease and Atrial Fibrillation
}

\author{
The Use of Non-Vitamin K-Dependent Anticoagulants and Vitamin K Antagonists \\ by Prof. Dr. med. Gunnar H. Heine, Prof. Dr. med. Vincent Brandenburg, and PD Dr. Dr. med. Stephan H. Schirmer in issue 17/2018
}

\begin{abstract}
Biased Results Owing to Competing Interests?
On the basis of the results of a selective literature search, the authors recommend in patients with renal insufficiency (creatinine clearance $>25-30 \mathrm{~mL} / \mathrm{min}$ ) the preferential use of NOAC in atrial fibrillation (1). In this, they take recourse-among others - to the guideline of the European Society of Cardiology (ESC), whose quality and validity is restricted by the fact (among others) that all guideline authors, including the lead authors, have relevant financial conflicts of interest, and the ESC does not apply rules on how to deal with conflicts of interest (2). The authors of the present article also have relevant conflicts of interest: Professor Heine has received moneys from two NOAC manufacturers, Professor Brandenburg from three NOAC manufacturers, and Dr. Schirmer from all five NOAC manufacturers. The result of their selective literature search reflects the interests of the pharmaceutical companies.
\end{abstract}

Their findings contradict the recommendations of authors who did not receive moneys from NOAC manufacturers - for example, the Drug Commission of the German Medical Association, and, with only one exception, the working group "Heart-Kidney" of the German Society for Cardiology-Heart and Circulatory Research and the German Society of Nephrology $(3,4)$. These authors advise against the use of any NOAC in a creatinine clearance $<30 \mathrm{~mL} / \mathrm{min}$. Other experts too recommend preferential use of vitamin $\mathrm{K}$ antagonists for the purpose of anticoagulation in patients with renal insufficiency (Der Arzneimittelbrief 2017, 51, 87).

Particularly if there is insufficient evidence from studies, recommendations for the treatment of patients should be made only by authors who do not have any conflicts of interest owing to financial relationships with pharmaceutical companies.

DOI: $10.3238 / a r z t e b l .2018 .0606 a$

\section{References}

1. Heine GH, Brandenburg V, Schirmer SH: Oral anticoagulation in chronic kidney disease and atrial fibrillation-the use of non-vitamin $\mathrm{K}$-dependent anticoagulants and vitamin $\mathrm{K}$ antagonists. Dtsch Arztebl Int 2018; 115: 287-94.

2. ESC-Leitlinienbeurteilung bei leitlinienwatch.de; www.leitlinienwatch.de/ esc-leitlinie-zum-management-des-vorhofflimmerns-esc-guidelinesfor-the-management-of-atrial-fibrillation/ (last accessed on 11 May.2018).

3. Leitfaden "Orale Antikoagulation bei nicht valvulärem Vorhofflimmern" (2nd, revised edition 2016), https://akdae.de/Arzneimitteltherapie/LF/ PDF/OAKVHF.pdf (last accessed on 11 May.2018).

4. Schlieper G, Schwenger V, Remppis A: [Anticoagulation in patients with chronic kidney disease: Recommendations from the working group "Heart-Kidney" of the German Cardiac Society and the German Society of Nephrology]. Internist 2017; 58: 512-21.

\section{Dr. med. Gisela Schott, MPH}

Arzneimittelkommission der deutschen Ärzteschaft, Berlin gisela.schott@akdae.de

Dr.med. Niklas Schurig

Rastatt

schurig@mezis.de

\section{Conflict of interest statement}

Dr Schott is a member of MEZIS and collaborates in Leitlinienwatch [guideline watch, https://www.leitlinienwatch.de/].

Dr Schurig is a board member in MEZIS and collaborates in Leitlinienwatch.
In Reply:

We thank our correspondents for their comments, which underline our position-that there are not enough data on anticoagulation in chronic kidney disease (CKD) (1). We summarize from a clinicalscientific perspective:

- Data on anticoagulation in advanced CKD and atrial fibrillation are lacking.

- According to prescribing information, phenprocoumon is contraindicated in "manifest renal failure," but apixaban, edoxaban, and rivaroxaban are licensed for use in patients whose creatinine clearance is $15-30 \mathrm{~mL} / \mathrm{min}$.

- Recent studies have shown that vitamin K antagonists (VKA) are associated with vascular calcification processes as a result of an induction of vitamin K deficiency in the vascular wall (2). Such vascular calcifications are common in CKD patients.

- Post hoc analyses of the registration trials show that the relative advantage of NOAC over warfarin (better effectiveness and fewer hemorrhages) in 
advanced CKD (up to a creatinine clearance of $25-30 \mathrm{~mL} / \mathrm{min}$ [3]) is greater than in normal renal function.

- Patients taking VKA are more commonly affected by anticoagulation nephropathy than those taking NOAC, with a deterioration in renal function (4).

- Self-monitoring of VKA treatment by means of INR measurements increases the time period within the therapeutic target range and therapeutic effectiveness, but it does not lower the risk for severe hemorrhages (5).

Clinical research that leads to the use of novel medications costs billions Euros and is therefore only possible with industry funding. Public funding instruments, especially in Germany, are several orders of magnitude lagging behind the necessary investments. What is required is a link between academic science and industry partners, in order to drive medical progress and steer it on to an optimal course. In this scenario, disclosure of possible (!) conflicts of interest is crucial.

We would encourage all those who complain about potential conflicts of interest to participate actively in helping close gaps in the evidence in the sense of optimized patient care.

DOI: 10.3238/arztebl.2018.0606b

\section{References}

1. Heine GH, Brandenburg V, Schirmer SH: Oral anticoagulation in chronic kidney disease and atrial fibrillation-the use of non-vitamin K-dependent anticoagulants and vitamin $\mathrm{K}$ antagonists. Dtsch Arztebl Int 2018; 115: 287-94.

2. Andrews J, Psaltis PJ, Bayturan O, et al.: Warfarin use is associated with progressive coronary arterial calcification: Insights from serial intravascular ultrasound. JACC Cardiovasc Imaging 2017; pii: 1936-878X(17)30477-1.

3. Halvorsen $\mathrm{S}$, Atar D, Yang $\mathrm{H}$, et al.: Efficacy and safety of apixaban compared with warfarin according to age for stroke prevention in atrial fibrillation: observations from the ARISTOTLE trial. Eur Heart J 2014; 35: 1864-72.

4. Chan $\mathrm{YH}$, Yeh YH, Hsieh MY, et al.: The risk of acute kidney injury in Asians treated with apixaban, rivaroxaban,dabigatran, or warfarin for non-valvular atrial fibrillation: A nationwide cohort study in Taiwan. Int J Cardiol 2018; 265: 83-9.

5. Heneghan CJ, Garcia-Alamino JM, Spencer EA, et al.: Self-monitoring and self-management of oral anticoagulation. Cochrane Database Syst Rev 2016; 7: CD003839.

On behalf of the authors

Prof. Dr. med. Gunnar H. Heine

Saarland University Medical Center, Saarland University Faculty of

Medicine, Internal Medicine IV-Nephrology and Hypertension, Homburg gunnar.heine@uks.eu

Conflict of interest statement

Prof. Heine has received lecture honoraria from Daiichi Sankyo and

honoraria for consultancy services and conference delegate fees from Bristol-Myers Squibb.

\section{-O CLINICAL SNAPSHOT}

\section{Massive Mucoid Impactions in a 73-Year-Old Woman}

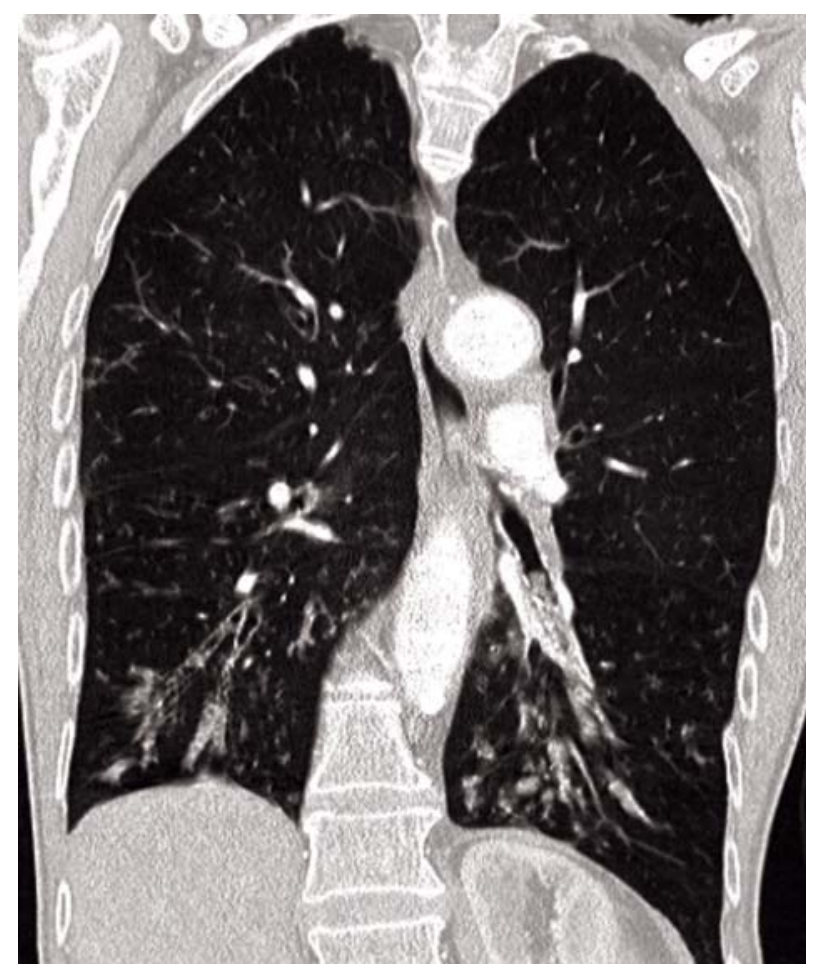

A 73-year-old woman was readmitted to the hospital with cachexia (BMI $14 \mathrm{~kg} / \mathrm{m}^{2}$ ). Chest CT again showed bilateral bronchiectasis in the lower lobes as first detected in 2012, this time with displacement of the lumina by large collections of exudate. Again, the patient declined invasive diagnostic endoscopy. The new CT featured a prominent left-sided fingerin-glove sign, indicating displacement of the major airways by mucus. Because clinical examination had shown exacerbated bronchiectasis (CRP on admission: $63.4 \mathrm{mg} / \mathrm{ll}[<5]$ ), she was treated with antibiotics and physiotherapy to mobilize the secretions, according to the guidelines. Disease processes that can lead to mucoid impaction-obstruction of the bronchi by inspissated mucus-are divided into obstructive versus nonobstructive or congenital versus acquired conditions. The differential diagnosis of diseases causing bronchiectasis is complex, but in the majority of cases the etiology can be discerned. Detection of bronchiectasis can have far-reaching consequences for treatment and sometimes for sociomedical management. Referral to a center with expertise in bronchiectasis is advisable.

Prof. Dr. med. Igor Alexander Harsch, Innere Medizin II, Thüringen Kliniken „Georgius Agricola“, Saalfeld/Saale, iharsch@thueringen-kliniken.de

Dr. med. Jana Kelterborn, Klinik für Diagnostische und Interventionelle Radiologie, Thüringen Kliniken "Georgius Agricola“, Saalfeld/Saale

Talaat Ghopreal, Innere Medizin I, Thüringen Kliniken „Georgius Agricola“, Saalfeld/ Saale

Conflict of interest statement: The authors declare that no conflict of interest exists.

Translated from the original German by David Roseveare

Cite this as: Harsch IA, Kelterborn J, Ghopreal T: Massive mucoid impactions in a 73-year-old woman. Dtsch Arztebl Int 2018; 115: 607. DOI: 10.3238/arztebl.2018.0607 